\title{
Acceptance of Social Media as a Marketing Tool : A Quantitative Study
}

\author{
Apeksha Hooda*, Ankur**
}

Received: December 29, 2017. Revised: February 17, 2018. Accepted: July 15, 2018.

\section{Abstract}

Purpose - The purpose of current paper is to identify features of advertisements at social media that generate the ad-click and to further identify if these advertisements lead to purchase. If no purchase is made, then reasons for not making purchase are identified. Users' purchase experience after users clicked at advertisements are also studied.

Research design, data, and methodology - Research design followed is exploratory research, where various factors leading to ad-clicks and generating purchase at social media platform were explored. Raw data was gathered by means of survey among a sample of 185 respondents in India using online structured questionnaire. GLM model and multinomial regression were used to analyze the data.

Results - Several factors including endorsement by friends, advertisement aesthetics, product reviews, and aggressive pricing played major role in generating ad-clicks. Major impediment to purchase on were product misrepresentation in advertisement, false discounts, and site security. Female users clicked more on social media advertisements and made more purchases compared to their male counterpart.

Conclusions - Social media advertisements have significant positive effect on buying behavior of online customers. Transactions culminating from social media ad-click generated significant positive experience for social media users. Thus, social media can be effective marketing tool.

Keywords: Social Media (SM), Social Media Marketing (SMM), Advertisement (Ad), Facebook, Buying Behavior.

JEL Classifications: M10, M20, M30, M31, M37.

\section{Introduction}

The rapid growth of social media platforms has permanently altered the way in which consumers interact with each other and organizations. Speed of online communications and numerous online information sources have made advertising at social media more lucrative (Duffett, 2015).

Historically main purpose of social media was to enable people with common interests to share information, and express opinions. However, social media use is no longer limited as a communication tool to the users sharing common interests (Barreto, 2013). Marketers have begun to realize the influence of social community in terms of interactivity that comprises of personalized sections, shopping experiences, greater convenience, and widespread information search (Duffett, 2015).

* First Author and Corresponding Author, Senior Research Fellow, Faculty of Management Studies, University of Delhi, Delhi, India. Tel: +91-9582388451, E-mail: apekshahooda.phd@fms.edu

** Manager HR, KEC International, RPG Group, Gurugram, India. E-mail: ankurhooda8@gmail.com
With the introduction of Web 2.0 technologies, human interaction with social media has reformed significantly. As a result, market analysis methodologies have undergone 360 degree change. Earlier businesses relied on field surveys to identify user preferences. Now same firms utilize social media sites like Facebook, Twitter to analyze users' preference, taste, and what they desire. Inexpensive access to the internet has opened up doors to social media marketing and made it possible for companies to reach out to millions of customers in a extolling way that was not previously possible(Hansson et al., 2013). Further, increased use of smartphones and mobile phones have also spurred the social media usage (Oviedo-García et al., 2014).

Few organizations will afford to forgo such opportunity cost of utilizing social media into its marketing strategy. But the problem in emerging countries is lack of research on utilization of social media as a marketing tool (Duffett, 2015). Previous researches on social media as a marketing tool are focusing more on identifying intention to purchase, attitude towards online shopping, consumer perception towards online shopping, shopping orientation, online shopping habit, website design and attributes, and demographic factors (Duffett, 2015; Gong et al., 2013; Jiang 
et al., 2013; Gehrt et al., 2012; Rajamma et al., 2009; Khalifa \& Liu, 2007; Monsuwéet et al., 2004). No study has been conducted on identification of social media advertisement features that would lead to ad-clicks. Until or unless advertisement is appropriate and objective, no consumer is going to click on it. It is imperative that businesses utilizing social media marketing have complete understanding of all advertisements' features that lead to ad-clicks, especially in terms of demographic characteristics of users clicking on advertisement. This will enable online retailers to target their marketing expenditure on those ad features and demographic characteristics that yield the maximum response. Thus, the current research has been undertaken with following objectives presented as research questions (RQ):

RQ1: Are advertisements posted at social media actually clicked by users and if yes, do they really lead to purchase?

First null Hypothesis has been formed here.

H01: Ads posted at social media has no significant positive influence on buying behavior of online customers.

RQ2: What factors refrain consumer from clicking ads posted at social media?

RQ3: What factors contribute to ad-clicks at social media?

RQ4: What factors refrain user from making purchase post clicking these ads?

RQ5: How is the user's purchase experience after adclicks at social media

Second null hypothesis has been formed here.

H02: Purchase made after user clicked advertisements at social media do not generate significant positive purchasing experience.

RQ6: How can social media improve in terms of its advertisement strategy?

RQ7: Do demographic factors viz. gender, age, income, and metro city dwelling have effect on decision to click ads and intention to purchase post clicking these ads at social media?

\section{Literature Review}

\subsection{Social Media and Marketing}

Social media is a technology under Web2.0 ambit, which allows like-mind people to come together in virtual world to create and exchange user-generated content, enable communications, and opinion sharing among themselves.

Whilst most users at social media have account primarily to remain in touch with family and friends than making new contacts, they are also well aware that social media is now widely used as a marketing channel for brands. Social media has enabled companies to spread their messages directly to the targeted audience in an effective manner and to build strong relationships with them (Hopkins, 2012). Social media marketing delivers both direct and indirect value to businesses (Hopkins, 2012). Past researches have confirmed that social media marketing do have positive influence on intention to purchase and final purchase (Duffett, 2015).

Since social media tools like Facebook are inexpensive, quick to set up, and do not require technical expertise to create a page or post an advertisement (Hopkins, 2012). Therefore, almost every business now has a Facebook page to mark its presence over social media where each and every user's action can minutely be followed (Vejacka, 2012). Facebook pages enable brand to attract more customers, identify online customers, effectively communicate with them, and understand their needs and expectations (Hopkins, 2012).

The rapid growth of social media platforms has altered the way the consumers interact with each other and organizations. Reaching out to millions of customers is no longer an issue (Hansson et al., 2013). What matters is how quickly brand is targeting its customer (Duffett, 2015). Using social media, customer can directly speak to the businesses about his/her desires. Therefore, when a business uses social media as a marketing channel, it has an opportunity to influence the quality of customer service (Duffett, 2015; Hansson et al., 2013; Hopkins, 2012).

Users' demographic characteristics play a major role in acceptance of social media as a marketing tool. Consumers' age, and income has significant effect on online shopping intention (Gong et al., 2013). However, there is no significant difference between advertisements seen and clicked among male and female (Barreto, 2013). A study by Duffett (2015) confirmed that there is no significant difference in terms of age and gender on intention to purchase and purchase perception of Facebook advertising.

\subsection{Advertisement Features at Social Media that Leads to Ad-click.}

Various advertisement features lead to different ad-clicks frequency. No previous study has exclusively focused on features of advertisements leading to ad-clicks. Very few studies mentioned features of advertisements in their study and no empirical study has been conducted. Product images/pictures are found to be most influential feature leading to ad-clicks (Hansson et al., 2013). Company's profile had some influence on user's behavior. Other attributes found to be influential are product review and recommendation by friends. Users rely more on the advice and suggestion of consumers who are already using the product than any professional critics (Barreto, 2013; Hansson et al., 2013; Kodjamanis \& Angelopoulos, 2013; Kodjamanis \& Angelopoulos, 2013; Hopkins, 2012). 


\subsection{Precariousness of Social Media Advertisement}

There are many precariousness of social media advertisements which refrain users from clicking ads, most notable are privacy and security concerns especially personal information thefts (Vejacka, 2012). Many users' give wary glance at these ads and think that these are merely a hogwash to steal their personal information (Vejacka, 2012). Mostly users use social media to remain in touch with the friends and to socialize (Hansson et al., 2013). Literature support evidence that users refrain from purchasing on social media when product range is different from what was shown in advertisement. Further fear of virus attack, and fear of personal information theft were deterrent (Hansson et al., 2013; Vejacka, 2012; Rajamma et al., 2009). Still, this form of social media marketing is gaining momentum. In fact, companies which are using social media are more connected to market trends as they are directly getting consumer input along with real time feedback (Hansson et al., 2013).

\subsection{Cynicism about Social Media Advertisement}

Despite marketing potential of social media sites, social media future can be endangered by a few cynicism (Vejacka, 2012). When ads are posted in users' profile, users should be allowed to search for the companies themselves, rather than bombarding users' profile with company messages (Hansson et al., 2013). Vejacka (2012) argued that many firms often try to lure users to their groups by using ostensible name or contents and later such groups are used to reach users by the commercial messages. Users targeted in this manner often rebuff such overtures and it has scandalous effect on company image. Therefore, brands are advised to seek user's preference if advertisements can be posted in his profile, ask for user's preference of advertisement that can be posted in his profile or post ads based on user's browsing history, and display images of only those products in advertisements that are really available (Hansson et al., 2013; Vejacka, 2012).

\section{Research Methodology}

\subsection{Research Design}

Research design followed is exploratory research, where various factors leading to ad-clicks and generating purchase at social media platform were explored. Facebook was chosen to study the acceptance of social media as marketing tool among Indian netizens since it is the most adopted social networking site in India (Statista, 2018) and it has average 1.4 billion daily active users as in December, 2017 (Facebook, 2018). Facebook's user base is still growing, thereby increasing its marketing and advertising potential (Vejacka, 2012).

\subsection{Design of Research Instrument and Data collection}

This section is divided into two phases:

1. Questionnaire Development

2. Data Collection and Data Analysis

\subsubsection{Phase 1: Questionnaire Development}

Owing to the non-availability of existing scales in literature in the context of reasons to click advertisements and reasons for not making purchase post clicking advertisements at social media, new scales were developed based on variables identified from literature review and interviews of fifty Facebook users residing in Delhi, National Capital Territory of India in the age group above twenty years.

Reliability of scale items used in Questionnaire was checked with Cronbach's alpha test $(<$ Table 1>). To ensure unidimensionality of scale w.r.t. reasons to click on ads and reasons for not making purchase post clicking these ads at Facebook, Exploratory Factor Analysis (EFA) was ran $(<$ Table 1>).

$<$ Table $1>$ Cronbach alpha test of reliability and EFA Results of Scale Unidimensionality.

\begin{tabular}{|c|c|c|c|c|c|}
\hline Reason to Click on Ads Indicators & $\begin{array}{c}\text { Factor } \\
\text { Loading }\end{array}$ & \begin{tabular}{|l|}
$\begin{array}{l}\text { Cronbach Alpha } \\
\text { (Reliability test) }\end{array}$ \\
\end{tabular} & $\begin{array}{l}\text { KMO Measure of } \\
\text { Sample Adequacy }\end{array}$ & \begin{tabular}{|c|} 
Bartlett's Test of \\
Sphericity(Significance) \\
\end{tabular} & $\begin{array}{c}\% \text { of Variance } \\
\text { explained }\end{array}$ \\
\hline Product image & .679 & \multirow{9}{*}{0.961} & \multirow{9}{*}{0.946} & \multirow{9}{*}{.000} & \multirow{9}{*}{82.887} \\
\hline Best deals available & .695 & & & & \\
\hline Diverse product range & .933 & & & & \\
\hline Product review & .944 & & & & \\
\hline Aesthetic look of advertisement & .947 & & & & \\
\hline Best product choice available & .978 & & & & \\
\hline Latest trend & .977 & & & & \\
\hline Viewing how product can be marketed at Facebook & .984 & & & & \\
\hline Friends recommendation & 988 & & & & \\
\hline Reasons for not making Purchase Indicators & & \multirow{8}{*}{0.752} & \multirow{8}{*}{0.886} & \multirow{8}{*}{.000} & \multirow{8}{*}{90.842} \\
\hline Paid shipping charges & .974 & & & & \\
\hline $\begin{array}{c}\text { Product range different from what shown in } \\
\text { advertisement image }\end{array}$ & .838 & & & & \\
\hline False claim on discounts and offers & .911 & & & & \\
\hline Product out of stock & .987 & & & & \\
\hline Server not available error & .994 & & & & \\
\hline Fear of virus attack & .976 & & & & \\
\hline Fear of stealing personal information & 981 & & & & \\
\hline
\end{tabular}


Phase 2: Data Collection and Analysis

\subsubsection{Sampling Method}

Snowball sampling method was used to identify the sample members where each respondent was asked to give reference of 10 people from whom questionnaire could be filled out. Facebook users based in India in the age group above 20 years were selected to fill in the questionnaire. Data was cross sectional in nature.

\subsubsection{Sample Size Determination}

Bartlett et al. (2001) suggested that if population is finite, variables in study are categorical in nature, and factor analysis technique has been used, then sample size should not fall below 100 observations and the ratio of observations to the independent variables should not fall below five else there will be a risk of overfitting. Considering these constraints along with non-respondents and missing data consideration, it was decided to keep sample size at 500 as it gave ratio of 55.5 with nine independent variables undertaken in current study, which is greater than the threshold value five. However, 206 filled questionnaires were received out of which 185 were valid. It was decided to conduct study with these many questionnaires as past studies on social media usage were conducted with even smaller sample size (Israel, 2013). KMO Measure of Sample Adequacy also supported the sample size (<Table 1>) (Hair et al., 2010).

\subsection{Data Analysis Tools used}

This study used statistical software named SPSS (version 23) to capture and analyze the data. Cronbach's alpha test was used to establish reliability of questionnaire scale items (Field, 2013; George \& Mallery, 2003). Further to ensure undimensionality of scale items, exploratory factor analysis was used (Field, 2013). Simple descriptive statistical measures (mean, standard deviation, frequencies) were employed to provide the basic description of results. One sample T-test was utilized to test the hypotheses, which is used when one independent variable need to be compared to an quantitative score (Field, 2013). ANOVA test was used to study the effect of Facebook user's demography on ad-clicks and purchase done. ANOVA used Wald chi square test and measured as Generalized Linear Model (GLM) to establish if there is significant difference in ad-clicks w.r.t. demographic factors and purchase done post clicking these ads w.r.t. demographic factors. Percentage method was used to establish differences, and to interpret the findings conclusively (Field, 2013). Multinomial regression was used to identify reasons to click on advertisements. To identify reasons for not clicking advertisements and to improve advertisement strategy, percentage method was employed owing to univariate and nominal variable analysis. To identify reasons for not making purchase after advertisement click, multiple response analysis was conducted. This is a bivariate analysis as two variables were analyzed here, namely, "Ad-clicks" and "Purchase done post clicking ads".

There was one open-ended question, which aimed to identify consumer's purchase experience after ad-clicks. This question was analyzed manually and result was drawn in the form of tree summary (<Figure $4>$ ).

\section{Results and Discussion}

\subsection{Respondent Details}

$<$ Figure 1> below provides the detail of respondents' w.r.t ad-clicks at Facebook.

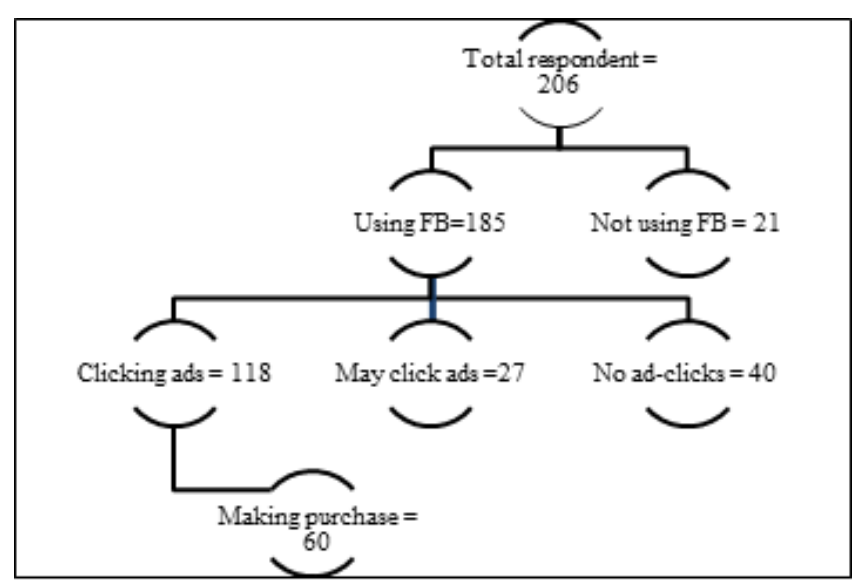

Source: Data Analysis using SPSS

<Figure 1> Respondents Detail

\subsection{Results based on Objectives}

RQ1: Are advertisements posted at social media actually clicked by users and if yes, do they really lead to purchase

The results of T-test indicated statistical difference between ad-clicks and no ad-clicks where $t=18, p<.05$. This study revealed that only $21.6 \%$ of respondents did not like to click on ads posted at Facebook. 14.6\% of respondents indicated that though they did not click on ads yet but may click in future. $63.8 \%$ respondents liked clicking on ads.

However, Facebook users did click advertisements posted at Facebook but they did not like to click advertisements more often (<Table 2>). When Z score of skewness and Z score of kurtosis was calculated, then $Z_{\text {skewnes }}$ Score $=.524 /$ $.223=2.35 ; Z_{\text {Kurtosis }}$ Score $=.294 / .442=0.66$.

Positive $\mathrm{z}$ value of skewness calculated above indicates too many low scores in the distribution (Field, 2013) which further confirmed that users' frequency of clicking 
advertisements was skewed more on left side of distribution which reflect 'normal frequency' and 'less than normal frequency' of clicking ads posted at Facebook(<Table 2>). Z value of kurtosis lying between -1.96 to 1.96 confirmed that data was normally distributed (Field, 2013) so distribution of response did not impose a problem.

$<$ Table 2> Ad-clicks frequency

\begin{tabular}{|c|c|c|c|c|c|c|}
\hline $\begin{array}{c}\text { Ad-click } \\
\text { Frequency }\end{array}$ & Frequency & $\begin{array}{c}\text { Valid } \\
\text { Percent }\end{array}$ & Skewness & $\begin{array}{c}\text { Std. Error } \\
\text { of } \\
\text { Skewness }\end{array}$ & Kurtosis & $\begin{array}{c}\text { Std. Error } \\
\text { of } \\
\text { Kurtosis }\end{array}$ \\
\hline Never & 7 & 5.9 & & & & \\
\cline { 1 - 3 } Sometimes & 46 & 39.0 & & & & \\
\cline { 1 - 3 } Normally & 47 & 39.8 & \multirow{2}{*}{.524} & .223 & .294 & .442 \\
\cline { 1 - 3 } Often & 13 & 11.0 & & & & \\
\cline { 1 - 3 } Always & 5 & 4.2 & & & & \\
\hline Total & 118 & 100.0 & & & & \\
\hline
\end{tabular}

$50.8 \%$ of users clicking advertisements went ahead with making purchase, thus ascertaining that social media users do like to click on advertisements and make purchase post clicking these advertisements.

When influence of Facebook advertisements on consumer buying behavior is analyzed using one sample T-test then these advertisements were found to have positive influence on buying behavior of consumers ( $t=5.877$ and $p<.05$ ), therefore null hypothesis $\mathrm{H} 01$ is rejected and it is concluded that advertisements posted at social media has significant positive effect on buying behavior of user.

RQ2: What factors lead to no click on advertisements posted at social media?

Majority of Facebook users in India who did not like to click on ads posted at Facebook, uses the same to remain in touch with friends rather than using the same as a shopping tool. Using percentage method, main factor leading to no ad-clicks at Facebook was identified as usage of Facebook mainly to remain in touch with friends $(50 \%$ contribution to reasons for no ad clicks). Additionally, users considered clicking advertisements posted at FB as wastage of time (27.5\% contribution to reasons for no ad clicks). Users preferred to use Facebook for socialization than for shopping ( $25 \%$ contribution to reasons for no ad clicks).

RQ3: What factors contribute to ad-click at social media?

Based on the results of multinomial regression, four main features were identified that led to ad-clicks at Facebook viz. best deals available (aggressive pricing), product review, aesthetic look of advertisements and friend recommendation with highest effect of friend recommendation followed by aesthetic look of advertisements, product review, and lastly best deals available(<Table $3>$ ). This model was found to be fit as $\chi^{2}(9,118)=24.363$ and $p<.05$ (Field, 2013).

<Table 3> Multinomial Regression result for reasons to click on ads

\begin{tabular}{|c|c|c|c|c|}
\hline \multirow[b]{2}{*}{ Factors } & \multirow{2}{*}{\begin{tabular}{|c|}
$\begin{array}{c}\text { Model Fitting } \\
\text { Criteria }\end{array}$ \\
-2 Log \\
Likelihood of \\
Reduced Model
\end{tabular}} & \multicolumn{3}{|c|}{$\begin{array}{l}\text { Likelihood Ratio } \\
\text { Tests }\end{array}$} \\
\hline & & $\begin{array}{l}\text { Chi- } \\
\text { Square }\end{array}$ & df & Sig. \\
\hline Product image & 56.096 & 1.343 & 1 & .246 \\
\hline Best deals available & 59.183 & 4.431 & 1 & $.035^{\star}$ \\
\hline Diverse product range & 55.173 & .420 & 1 & .517 \\
\hline Product review & 59.697 & 4.944 & 1 & $.026^{\star}$ \\
\hline Aesthetic look of advertisement & 64.019 & 9.266 & 1 & $.002^{*}$ \\
\hline Best product choice available & 55.901 & 1.149 & 1 & .284 \\
\hline Latest trend & 54.990 & .238 & 1 & .626 \\
\hline $\begin{array}{l}\text { Viewing how product can be } \\
\text { marketed at FB }\end{array}$ & 56.206 & 1.454 & 1 & .228 \\
\hline Friend's recommendation & 67.223 & 12.471 & 1 & $.000^{\star}$ \\
\hline
\end{tabular}

Note: df : Degree of freedom, Sig. : Significant value

* Likelihood ratio test showed significant value at $p=.05$

RQ4: What factors refrain user from making purchase post clicking these advertisements?

$49.2 \%$ of respondents clicked on ads but never made any purchase post clicking these ads. When their reasons for no purchase were analyzed using multiple response analysis, it was identified that $49.1 \%$ of non-buyers felt that product range was different from what shown in advertisement. $38.6 \%$ of non-buyers experienced false claim on discounts and offers. Safety was another concern that Facebook users quoted as a reason for not making purchase where fear of virus attack and fear of stealing personal information, collectively constituted $36.8 \%$ of valid response.

However, reasons viz. paid shipping charges, product out of stock, server not available, and other reasons were not very much evident in restricting user from making purchase online.

RQ5: How is the user purchasing experience post clicking ads at social media?

$50.8 \%$ of respondents clicking ads made purchase and when their response regarding purchase experience was analyzed then it was found out that only $11.6 \%$ of users had bitter experience post purchasing. Main reason identified for bad experience was that product delivered was not same as displayed in advertisement posted at Facebook. However, many respondents quoted that experience is not related to purchase through Facebook but depends on specific website. Facebook just hosts the link of seller's page. Few respondents made the point that it was bit tougher to get misfit products exchanged than e-retailers' sites like Amazon. 


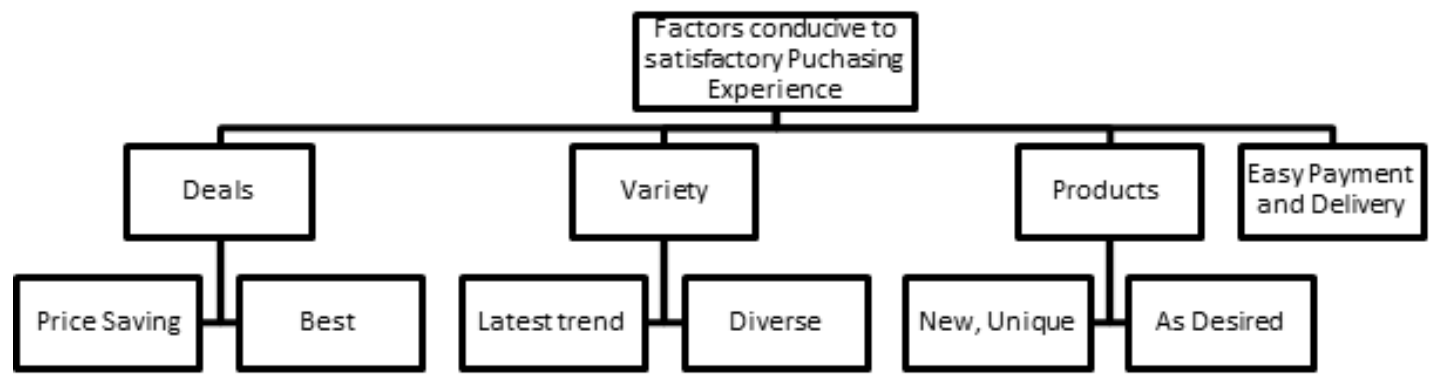

Source: Based on response analysis of an open ended question

<Figure 2> Respondent Experience making purchase post clicking Ads at Facebook.

Purchase done post-clicking ads posted at social media generated significant positive purchasing experience. $46.7 \%$ of respondents had satisfactory purchase experience and $41.7 \%$ has neutral experience post clicking the ads. One sample T-test result, $t=12.093, \quad p<.05$, rejected Null Hypothesis H02. Thus, it is concluded that purchase done post-clicking ads at social media does generate significant positive purchasing experience.

<Figure 2> below presents the summarized analysis of open-ended question regarding the factors leading to satisfactory purchase experience post clicking the ads posted at Facebook.

RQ6: How can social media improve in terms of its advertisement strategy?

Majority of respondents believed that advertisements posted at Facebook showed images of products that were different from what they really were where $49.2 \%$ of respondents who clicked on the ads gave the recommendation that advertisements should show the images of products that are available. $24.6 \%$ of respondents suggested that Facebook should ask for user preference, if ads can be posted in his profile, and $23.7 \%$ of respondents suggested that Facebook should ask for user preference of ads that can be posted in its profile.

However, respondents had given other suggestions also, apart from what were mentioned in survey instruments. They desired that user permission should be sought to display ads based on his browsing history, illogical advertisements should be banned, and deliver what company promises or shows.

RQ7: Do demographic factors viz. gender, age, income, and metro city dwelling have effect on intention to click on advertisements and intention to purchase post clicking these advertisements at social media?

GLM ANOVA as discussed in prior text was used, since data contains different number of observations for some independent variables which can be observed by larger standard error (Field, 2013; George \& Mallery, 2003).

$<$ Table $4>$ and <Table 5> below shows the demographic effect in terms of Wald chi square test. The Wald chi square test revealed that there is no significant impact of demographic factors except of gender, on decision to click on ads and decision to make purchase post clicking these ads at $p=.05$.

<Table 4> Effect of demographics on decision to click advertisements at Facebook

\begin{tabular}{|c|c|c|c|}
\hline Demographic Factor & Wald Chi-Square & df & Sig. \\
\hline Age & 9.232 & 5 & .100 \\
\hline Gender & 4.374 & 1 & $.036^{*}$ \\
\hline Individual Monthly Income & 5.797 & 4 & .215 \\
\hline Metro City & .043 & 1 & .835 \\
\hline Occupation & 7.563 & 7 & .373 \\
\hline
\end{tabular}

Note: *Wald chi square test showed significant difference at $p=$ .05 .

<Table 5> Effect of demographics on decision to purchase postclicking advertisements at Facebook

\begin{tabular}{|c|c|c|c|}
\hline Demographic Factor & Wald Chi-Square & df & Sig. \\
\hline Age & 3.649 & 5 & .601 \\
\hline Gender & 4.026 & 1 & $.045^{\star}$ \\
\hline Individual Monthly Income & 2.400 & 4 & .663 \\
\hline Metro City & .214 & 1 & .644 \\
\hline Occupation & 6.967 & 7 & .432 \\
\hline
\end{tabular}

Note: *Wald chi square test showed significant difference at $p=$ 05 .

Gender showed strong impact on choice of clicking advertisements and choice of making purchase post clicking these advertisements whereby female clicked advertisements (\%age $=43.8 \%)$ more than male $(\% a g e=34.6 \%)$ and females $(\%$ age $=68.3 \%)$ made more purchase than males $(31.7 \%)$.

\subsection{Hypotheses Result}

$<$ Table 6> below summarizes the result of hypotheses testing. 
$<$ Table 6> Results of Hypotheses testing using SPSS.

\begin{tabular}{|c|c|c|c|}
\hline S No & Null Hypotheses & Method used & Findings \\
\hline H01 & $\begin{array}{c}\text { Ads posted at social media has no significant positive effect } \\
\text { on buying behavior of online customers. }\end{array}$ & One sample T Test & $\begin{array}{c}\text { Null hypothesis Rejected } \\
(p<0.05)\end{array}$ \\
\hline H02 & $\begin{array}{c}\text { Purchase done post-clicking ads posted at social media does } \\
\text { not generate significant positive purchasing experience. }\end{array}$ & One sample T Test & $\begin{array}{c}\text { Null hypothesis Rejected } \\
(p<0.05)\end{array}$ \\
\hline
\end{tabular}

\section{Conclusion}

Owing to increasing influence of social media on human activities, companies are vigorously trying to utilize the power of social media to build their presence in virtual market and market their products and services (Mariani, Di Felice, \& Mura, 2016). This study has clearly demonstrated that social media users do like to click on advertisements posted at social media platform and make purchase at social media sites, thereby indicating that consumers have started accepting social media as a clout for marketing and do not use it merely as a social engine. Furthermore, this paper makes the noteworthy contribution towards the social media marketing research in emerging countries where dearth of research exist in effective utilization of social media as a marketing tool.

This investigation has a few limitations and lends itself to further research. One limitation is limited literature review owing to dearth of study regarding the factors leading to ad-clicks and generating online purchase. Additionally, this study is based on only one Social Networking Site (SNS) whereas future research can be undertaken considering Google+, Linkedln, Twitter, and YouTube. This study only provides the silhouette of advertisement features that lead to ad-clicks. Future research can consider the deployment of neural networks to develop a qualitative model of advertisement features leading to acceptance of social media as a marketing tool among netizens. Sample size taken was smaller and sampling method used was snowball sampling, which is a non-probability method of sampling (Atkinson et al., 2004). Future research can employ random sampling method. Further, current study is based on social media users in India. However, future research could consider other developing nations and conduct comparative study.

\section{References}

Atkinson, R., \& Flint, J. (2004). Encyclopedia of Social Science Research Methods. London, UK: Sage Publications.

Barreto, A. M. (2013). Do users look at banner ads on Facebook?. Journal of Research in Interactive Marketing, 7(2), 119-139.

Bartlett, J. E., Kotrlik, J. W., \& Higgins, C. C. (2001). Organizational research: Determining appropriate sample size in survey research appropriate sample size in survey research. Information Technology, Learning, and Performance Journal, 19(1), 43.

Duffett, R. G. (2015). Facebook advertising's influence on intention-to-purchase and purchase amongst Millennials. Internet Research, 25(4), 498-526.

Facebook. (2018). Company information. Retrieved February 16, 2018 from https://newsroom.fb.com/ company-info/

Field, A. (2013). Discovering Statistics Using SPSS. London, UK: Sage Publications.

Gehrt, K. C., Rajan, M. N., Shainesh, G., Czerwinski, D., \& O'Brien, M. (2012). Emergence of online shopping in India: Shopping orientation segments. International Journal of Retail \& Distribution Management, 40(10), 742-758.

George, D., \& Mallery, P. (2003). SPSS for Windows Step by Step: Answers to Selected Exercises. $A$ Simple Guide and Reference, 63. https://doi.org/9780335262588

Gong, W., Stump, R. L., \& Maddox, L. M. (2013). Factors influencing consumers' online shopping in China. Journal of Asia Business Studies, 7(3), 214-230.

Hair, J. F., Black, W. C., Babin, B. J., \& Anderson, R. E. (2010). Multivariate Data Analysis (7th ed.). Upper Saddle River, NJ: Prentice Hall.

Hansson, L., Wrangmo, A., \& Søilen, K. S. (2013). Optimal ways for companies to use Facebook as a marketing channel. Journal of Information, Communication and Ethics in Society, 11(2), 112126.

Hopkins, J. L. (2012). Can Facebook be an effective mechanism for generating growth and value in social media all businesses?. Journal of Systems and Information Technology, 14(2), 131-141.

Israel, G. D. (2013). Determining Sample Size. Agricultural Education and Communication Series, 2009(4), 1-5.

Jiang, L. A., Yang, Z., \& Jun, M. (2013). Measuring consumer perceptions of online shopping convenience. Journal of Service Management, 24(2), 191-214.

Khalifa, M., \& Liu, V. (2007). Online Consumer Retention: Contingent Effects of Online Shopping Habit and Online Shopping Experience. European Journal of 
Information Systems, 16, 780-792.

Kodjamanis, A., \& Angelopoulos, S. (2013). Consumer Perception and Attitude towards Advertising on Social Networking sites: The case of facebook. Proceedings of the International Conference on Communication, Media, Technology and Design. Famagusta - North Cyprus.

Mariani, M. M., Di Felice, M., \& Mura, M. (2016). Facebook as a destination marketing tool: Evidence from Italian regional Destination Management Organizations. Tourisocial Media Management, 54, 321-343.

Monsuwé, T. P. Y., Dellaert, B. G. C., \& Ruyter, K. De. (2004). What drives consumers to shop online? A literature review. International Journal of Service Industry Management, 15(1), 102-121.

Oviedo-García, M. Á., Muñoz-Expósito, M., Castellanos-
Verdugo, M., \& Sancho-Mejías, M. (2014). Metric proposal for customer engagement in Facebook. Journal of Research in Interactive Marketing, 8(4), 327-344.

Rajamma, R. K., Paswan, A. K., \& Hossain, M. M. (2009). Why do shoppers abandon shopping cart? Perceived waiting time, risk, and transaction inconvenience. Journal of Product \& Brand Management, 18(3), 188-197.

Statista. (2018). Penetration of leading social networks in India as of third Quarter 2017. Retrieved February 16, 2018 from https://newsroom.fb.com/company -info/

Vejacka, M. (2012). Facebook advertising and its efficiency on the Slovak Market. $E \& M$ Ekonomie a Management, 15(1), 116-127. 